\title{
14
}

\section{China's resources demand at the turning point}

\section{Ross Garnaut and Ligang Song}

China has contributed a majority of the increase in global demand for energy and metals over the early twenty-first century. In the first years of the century, with global economic growth subdued in the aftermath of the collapse of the technology boom, this moderated what would otherwise have been large falls in commodity prices. In more recent years, with recovery in the United States and Europe, and then the end of the long Japanese stagnation, it has been the driving force behind the lifting of energy and metals prices to levels that have only been seen before at high points of sustained global prosperity or, in the case of petroleum, major disruption to supplies entering world markets. This has transformed the immediate economic prospects of a wide range of countries with comparative advantage in the natural resource-based industries, including Australia, Papua New Guinea and Russia in China's Western Pacific neighbourhood, and beyond that in Central Asia, the Middle East, Africa and Latin America. At the same time, it has raised challenges for economies that are poorly endowed with natural resources, and questions about global environmental amenity.

How has the large recent lift in global energy and metals prices related to Chinese economic growth? Is it a temporary phenomenon, that will pass with some adjustment to Chinese or global demand or expansion of supply? Will scarcity and rising prices for resources, and the environmental management challenges with which they are associated, threaten the sustainability of rapid economic growth in China? In particular, how does it relate to the turning point in Chinese economic development? 


\section{An old story}

No economically valuable resources are scarce in nature in an absolute, as distinct from an economic, sense. If demand rises for some source of energy or metal, the price tends to rise. This encourages substitution in demand. It causes the owners of existing mines to drive them harder to produce more through various modifications to production processes. It causes firms with relevant capacities to invest more in exploration for more potentially profitable mines, and to build new mines. Sometimes the development of new mines in new mining regions requires large investments in transport capacity and infrastructure, and even longer-term investments in the development of new economic institutions. Through some combination of adjustments to demand and supply, at some price and expectation of future prices, a balance will come to be struck.

It is usually possible for a mining firm to increase output modestly from established mines at relatively low cost. On the other hand, the establishment of new mines is usually highly expensive. It follows that if global demand grows at a moderate pace - say, at a couple of per cent per annum - relatively low prices will attract enough expansion of supply to keep the market in balance. But beyond some rate of growth in global demand for each commodity, prices will have to be high enough—or rather, expected future prices will need to be high enough—to cover not only the cost of producing minerals from established mines, but also to secure recovery of large capital expenditure in exploration and new mine development, together with a return on that investment that exceeds its supply price (Garnaut and Clunies Ross, 1983; Garnaut and Song, 2006; Garnaut, 2006).

It follows that world prices for energy and metals at any time tend to be on one of two tracks. If the growth in world demand is such that it can be met by incremental expansion from existing mines, average prices may be little higher than is necessary to cover the current costs of production in higher cost established mines. But if growth in world demand is expected to be so rapid that many new mines are required to meet it, prices will be on a much higher track, at levels that will justify large amounts of new investment.

The real world of minerals and energy prices is complicated by uncertainty about all of the factors that affect expectations of future demand, of costs of expanding future output, and therefore of price. Changes in expectations will generate large fluctuations in price around average levels of either the lower or higher track. The fluctuations in price are most extreme when fluctuations in either real conditions or expectations of them are so large that they cause switches from one of the average price tracks to the other. Fluctuations in energy and 
minerals prices are a management challenge both to economies with comparative disadvantage (importers of commodities) and advantage (exporters) in their production. In this chapter we focus on the longer term determinants of average prices rather than on their short-term fluctuations.

Over the history of modern economic development, there have been some long periods during which the rate of expansion of economic activity has been relatively strong in economies in the middle stages of industrialisation, and in which the intensity of energy and metals use has risen rapidly, and others when it has been tepid. To paint the historical picture with the broadest of brushes, the several decades before the First World War can be recognised as a period of strong economic expansion in newly industrialising economies (broken by a serious downturn in the early 1890s), with rapid industrialisation of Germany and the United States as they moved towards the global technological frontiers that were being advanced in the United Kingdom. The First World War ushered in several decades of relative stagnation—not everywhere or in every year, but generally and on average. Demand for energy and metals was temporarily boosted and then deflated by war and the associated destruction of economic capacity. The long stagnation was followed by a long boom, commencing with reconstruction in Japan and Europe through the 1950s. This was enhanced and extended by sustained rapid growth in Japan until that country, was approaching the global productivity frontiers in the early 1970s, with the extension ending sharply in 1974 with the oil crisis and recession. From then until the turn of the twenty-first century, rapid growth in newly industrialising economies in East Asia, including China from the beginnings of reform in the late 1970s, offered some leavening of a slowly growing global lump. But at first this was in relatively small economies and from a low base, so that the average contribution to global growth in demand for energy and metals was modest.

By the early twenty-first century, the Chinese economy had been growing rapidly for long enough to be a substantial component of the global economy. This was more obvious when purchasing power rather than national accounts at current exchange rates was used as a basis for comparison-and it is purchasing power that is relevant in assessing the impact of Chinese demand on global energy and metals markets (see the discussion in Wang (this volume, Chapter 3). Continued rapid growth in China from that time had a large impact on the balance between the world's supply and demand for a wide range of commodities.

The growth in Chinese demand derived to a considerable extent simply from growth in the economy. But it was enhanced by the stage of economic development that China had reached by the early twenty first century. The advancing state of urbanisation, the increase in economic activity and incomes to the point where 
comparative disadvantage in natural resource-based products was manifested in rapidly growing import propensities, the structural shift from comparative advantage in relatively labour-intensive to more capital-intensive production, and the increasing export orientation of the economy-features associated in some ways with the turning point in Chinese economic development-all magnified the effects of aggregate demand growth on pressures on global commodity markets.

Continued rapid growth in the Chinese economy from a much higher base and changes in economic structure interacted to increase China's import demand for a wide range of minerals rapidly. The effect was large enough to usher in a third period of exceptional growth in world demand for energy and minerals, tending to require relatively high prices to induce the necessary expansion of supply.

Why only tending to require high prices? Because the expected prices that are necessary to encourage an adequate level of investment depend on supply conditions in particular industries. Later we illustrate these generalisations with specific empirical examples, for copper and energy.

\section{The turning point, structural change and demand for minerals in Northeast Asia}

The 'turning point in economic development' derives from Lewis' (1954) celebrated article on economic development in a surplus labour economy (see also Chapters 1 and 2, this volume). The concept was elaborated and applied explicitly to the densely populated economies of East Asia, first of all Taiwan, by Fei and Ranis (1964), and tested for the Japanese case by Minami (1973).

The central idea is that in a densely populated and underdeveloped economy, with population concentrated in the rural sector, the average marginal product of labour in agriculture is very low, in the extreme zero. Marginal product in modern sector employment in urban areas is positive. Total economic output can proceed rapidly for a considerable time through the transfer of labour from low productivity employment in rural areas to more productive modern sector employment, without significantly increasing the cost of labour in either sector. During the potentially long period of extensive economic growth, the rapidly growing economy's comparative advantage remains concentrated in labour-intensive activities, which happen generally to require relatively low inputs of energy and minerals.

Rapid economic growth in the modern sector continues to absorb labour from the countryside, until labour is no longer in abundant supply. The removal of surplus labour from the countryside eventually raises per capita endowments of land and other economic resources to the point where marginal product as well as average output per worker rise significantly, Wages have to rise in modern sector employments 
if labour is to continue to be attracted from the countryside. By this stage, the scale of modern and urban employment is considerable, so that a given rate of increase is associated with large absolute increases in demand for labour. Real wages and urban purchasing power increase rapidly. Rising labour costs also force a shift in comparative advantage in international trade, from labour-intensive to more capitalintensive production using energy and metals much more intensively.

Something like this has happened in most of the countries that are now developed-excepting only those like Australia and New Zealand which were born into the modern economic world already rich from their abundant per capita natural resource endowment. The model fits most closely the Northeast Asian economies that have experienced rapid economic growth involving the absorption on a huge scale of surplus labour from rural areas into modern sector employment. It fits Northeast Asia most closely because Japan, the Republic of Korea and at least one coastal province of China with one third of the country's population are amongst the most densely populated on earth, with the poorest per capita endowments of natural resources; and because they each had great capacity for rapid economic growth once certain conditions had been met. Even Hong Kong through the decades of early industrialisation met the conditions of the surplus labour growth model, when the countryside from which it drew large amounts of unskilled labour was its mainland hinterland.

Much can be learned about the likely relationship between growth and demand for resources in China in the period ahead, from the experience of its Northeast Asian neighbours in their own periods of industrial transformation. Somewhere in the per capita income range of US\$2,000-5,000 in today's values, the metals on and energy intensity of economic growth increased, and then stayed at high levels until, in Japan's case, at per capita incomes of about US\$20,000, there was a marked reduction (Figure 14.1). Figure 14.3 shows that the general relationships observed in Northeast Asia between per capita incomes and metals' use has global analogues. Korea's intensity of metals and energy use has tended to be higher than Japan's at any given level of income. The metal intensity of production and growth has tended to be high by global standards in all Northeast Asian economies, and particularly high in Korea. China so far lies between the Japanese and Korean intensities, but closer to the higher Korean numbers. Low per capita resource endowments have made all Northeast Asian economies exceptionally dependent on imports. Energy intensity of production and growth has been lower than the global average in Japan, and higher in Korea. China's energy intensity so far has been even higher than Korea's, especially in the form of coal, in which China's domestic endowments are large. 
Figure 14.1 Total energy consumption intensity: China, Japan and Korea

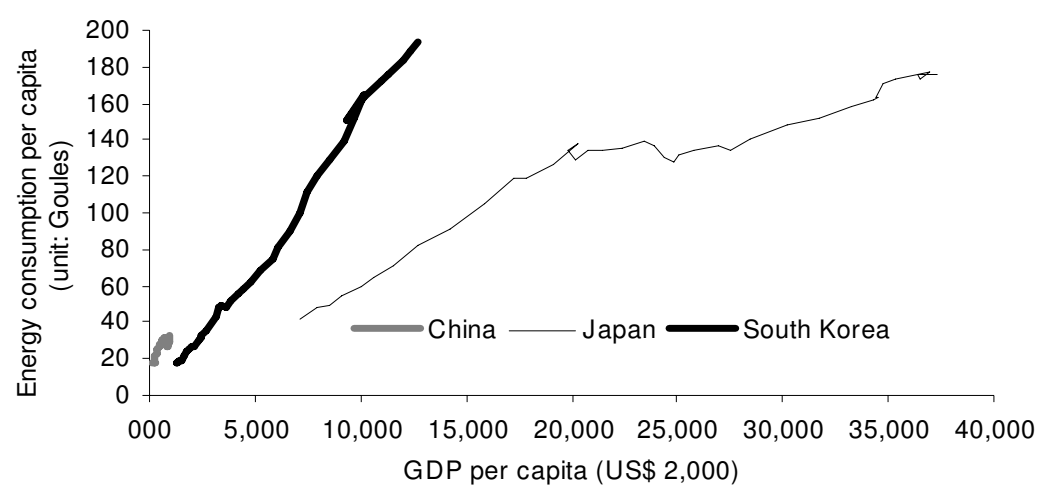

Note: Based on national accounts GDP at 2000 constant US dollar price.

Source: Authors' calculations with data from US Department of Energy and World Bank.

\section{Figure 14.2 China's coal consumption in comparison with East Asian} economies

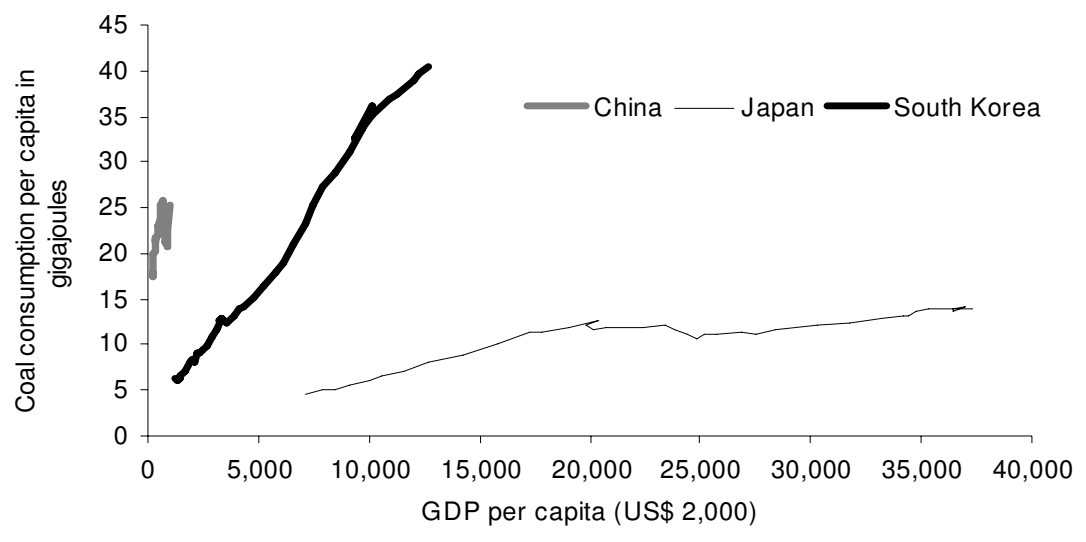

Note: Based on national accounts GDP at 2000 constant US dollar price.

Source: Authors' calculations with data from US Department of Energy and World Bank. 
Figure 14.3 Steel demand and economic growth in Northeast Asia (using PPP exchange rates for China)

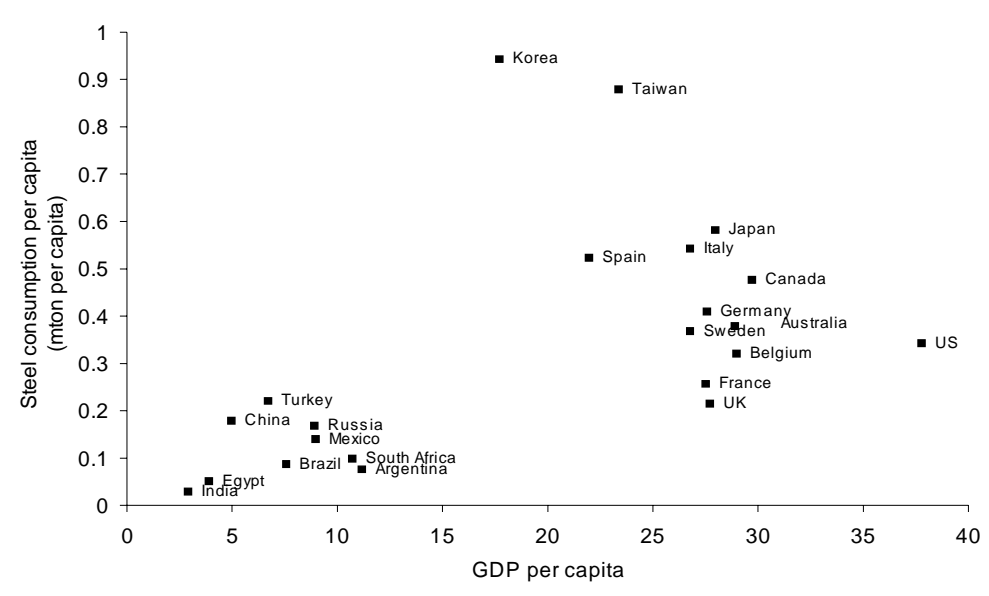

Source: Data from Westpac Economic Research.

What structural factors drive the differences in metals and energy intensities of growth at different stages of development and across countries? Three variables are especially powerful: the investment share of output; the export share of production; and the proportion of population living in urban areas.

Let us first examine the investment share of economic output. There is a general tendency for the energy and metals intensity of investment to be higher for investment than other components of national production (Table 14.1). This is a source of unusually high metals and energy intensity of production in Northeast Asian economies at their times of rapid growth as exceptionally high investment shares have been a characteristic of rapid growth in Northeast Asian.

China in recent years has been exceptional even in Northeast Asia for its high sustained investment shares of GDP (Figure 14.4). The exceptional Chinese investment share shows no sign of falling (Garnaut and Huang 2005), and can be expected to support unusually high metals and energy intensity of growth in China for the foreseeable future.

A second is the export orientation of production—-beyond the point at which labour begins to become scarce, wages rise and comparative advantage and export specialisation shift from labour-intensive towards more capital-intensive products. China's export orientation is shaping up to be relatively high on a global scale. 
Table 14.1 China's shares of energy and metal products in investment, exports and outputs, 1997 and 2000 (per cent)

\begin{tabular}{lrrrrrr}
\hline Sector & \multicolumn{2}{c}{ Investment } & \multicolumn{2}{c}{ Export } & \multicolumn{2}{c}{ Total output } \\
& 1997 & 2000 & 1997 & 2000 & 1997 & 2000 \\
Coal and petroleum & 2.09 & 5.58 & 1.51 & 1.92 & 1.91 & 3.35 \\
Metal product & 11.29 & 13.56 & 6.94 & 7.81 & 6.25 & 6.28 \\
\hline
\end{tabular}

Source: Calculated using the Input-Output Tables of China: 1997 and 2001

Within Northeast Asia, export orientation is much greater than Japan, but less than Korea. It is still rising strongly, and will continue to do so, through a period in which most of the growth in Chinese exports is outside the labour-intensive items that dominated in the early period of rapid internationally oriented growth.

A third is the level of urbanisation. Figure 14.5 shows the general tendency for per capita use of steel to rise with the proportion of people living in urban areas, until a ratio of around 60 per cent has been reached. China's early industrialisation was characterised by articificial constraints on rural-urban migration. As a consequence, the urban proportion of the Chinese population remains considerably lower than in other countries, historically and in the contemporary world, at similar levels of development. The absolute constraints on movement have now been removed for practical purposes, but disincentives to movement remain (Chapter 10 by $\mathrm{Du}$, Greogory and Meng, this volume). The removal of the absolute constraints, the likely amelioration of the current disincentives, and the large and increasing differentials between rural and living standards are likely to lead to an increase in the rate of migration in the years ahead, and to an exceptional contribution from rapid urbanisation to growth in demand for metals and energy.

For all of these reasons, the strong growth in demand for metals and energy in China is likely to continue through the period of rapid industrial transformation that will be associated with strong economic growth over the next two decades. The increasing absolute and relative size of the Chinese economy will magnify the impact on world markets beyond the high levels experienced in the recent past (Figures 14.6 and 14.7). At the end of this period, on the assumption of no dislocation to the Chinese growth process, China is likely to account for greater consumption of energy and metals than all of the currently industrial economies today.

It may be useful to underline some of the points made in this chapter about growth in demand for resources in general, with a closer look at copper and energy. 
Figure 14.4 Long-run investment shares of GDP: China, Japan, Korea and India, 1965-2004

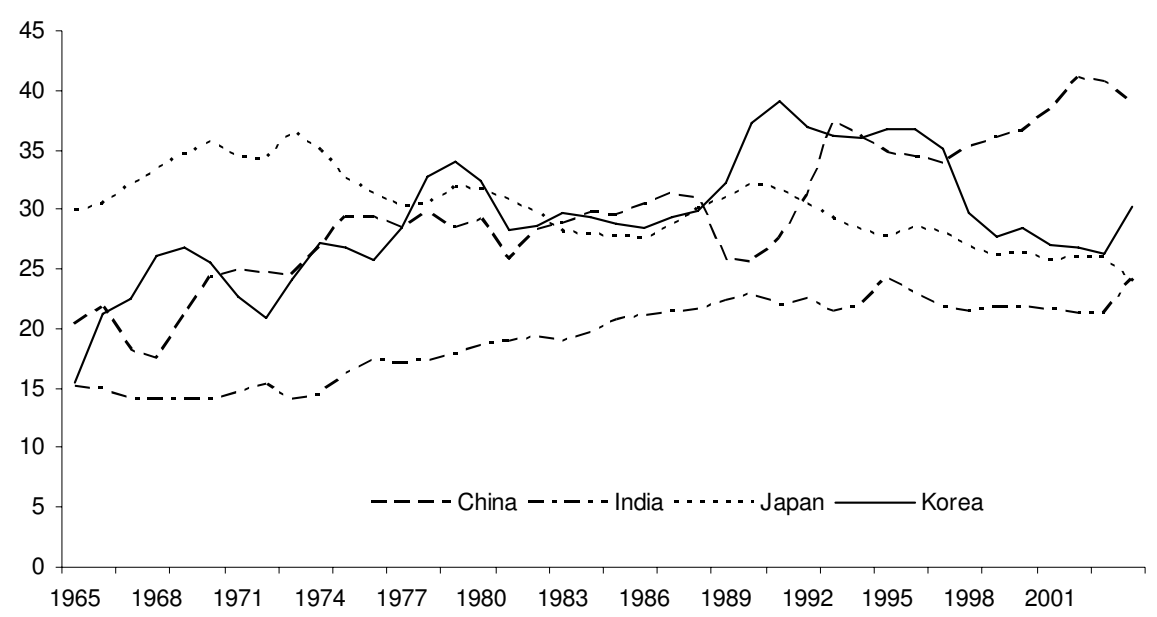

Source: Calculated using the data from Garnaut and Huang (2005) and the World Bank.

\section{Figure 14.5 Steel consumption per capita with urbanisation}

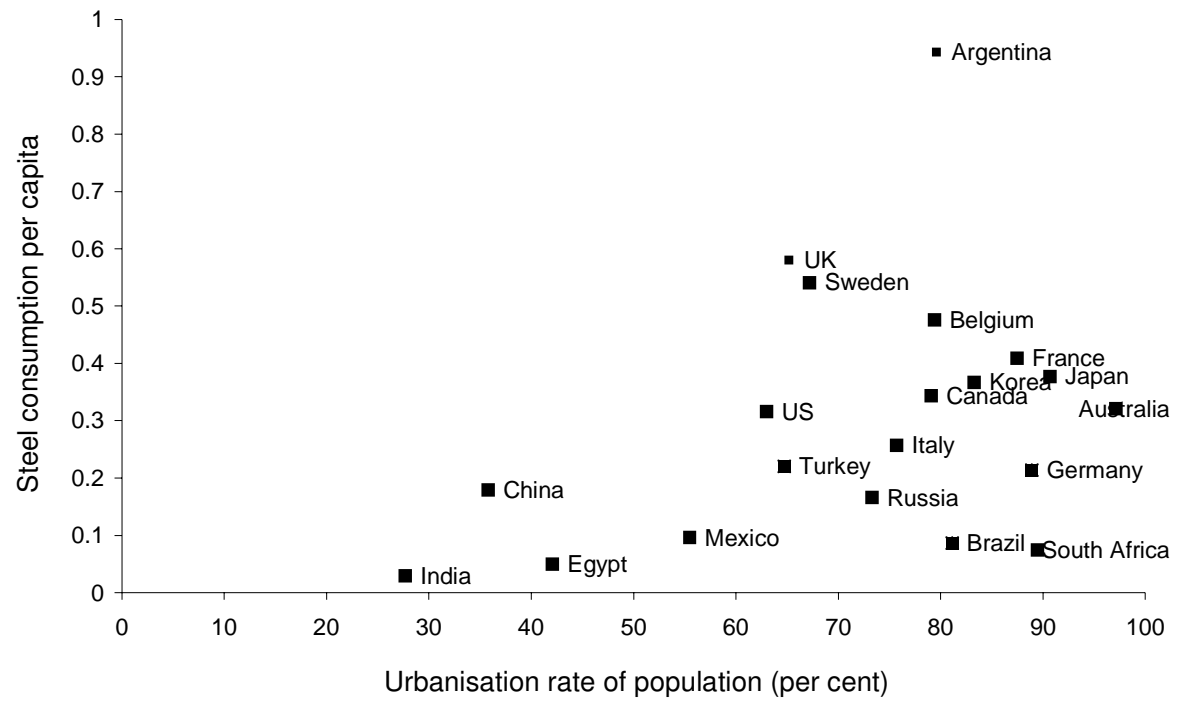

Note: Urbanisation is defined as the ratio of urban population in total population.

Source: Plotted using the data from Westpac Economic Research. 


\section{The case of copper}

Per capita global copper consumption has been highly sensitive to average global incomes. It has fallen sharply in any setback to incomes in depression and recession, and risen with incomes growth (Figure 14.8). The periods of most rapid consumption growth have been those when large economies have been experiencing rapid industrialisation, at a time of relatively buoyant global economic conditions. The rapid growth in Japan in the 1960s to 1974 is the most recent completed episode of such accelerated demand growth. The world seems to have entered another such period with the rapid industrialisation of China in the early twenty first century.

Figure 14.9 makes the point that there is no long-term average copper price. The price in real terms can be well above or well below the long historical average according to whether the rate of increase in global demand is such as to require large additions of new capacity in mining. The periods up to and including the First World War and that from the late 1950s to 1974 stand out for the high average prices. The periods between the two World Wars and the last quarter of the twentieth century stand out for their relatively low average prices. Recent including current prices take us back into the range of the 1890 s and early twentieth century, and beyond the experience of the Japan boom of the 1960s and early 1970s to the historical peaks.

The extent to which the recent strong growth in demand is a 'China boom' is illustrated in Figure 14.10. As a result, the China share of total world demand for major industrial metals has risen steeply —although not for several metals in 2004when demand growth was checked temporarily by controls on investment expenditure (Figure 14.4). The increase in the Chinese share of global consumption over the past decade means that a given rate of growth in Chinese demand will have a larger impact on growth in world demand.

\section{The case of energy}

China is a substantial oil producer and by far the world's largest importer of coal. Unlike the case of metals, energy demand has therefore been met mainly from domestic resources. Indeed, China was a significant oil exporter in the early years of reform, and remained a coal exporter in the early twenty-first century. China became a large net importer of energy for the first time in 2005 (Figure 14.11).

China's energy demand has been growing more rapidly than economic output since 2002. This follows several years of relatively low energy intensity in economic growth, as distortions in the price system were removed with other parts of the 
Figure 14.6 Shares of petroleum consumption in the world: Japan, Korea, China and total Northeast Asia, 1960-2005 (per cent)

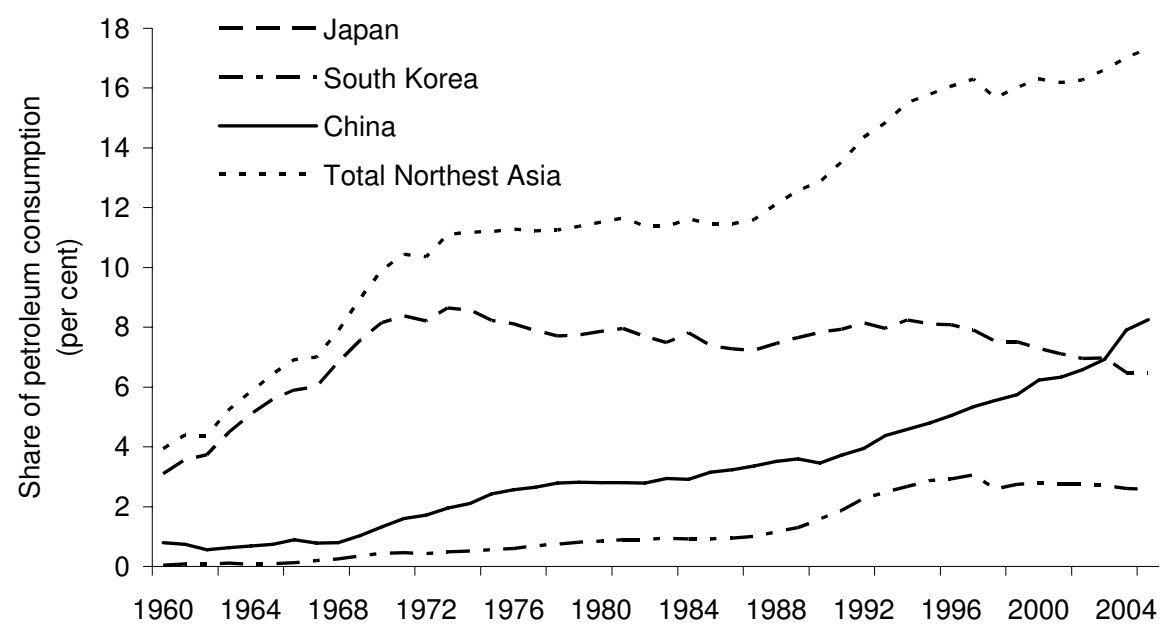

Source: Calculated using the data from US Department of Energy.

Figure 14.7 China's shares of incremental world demand for four metals, 1995-2005 (per cent)

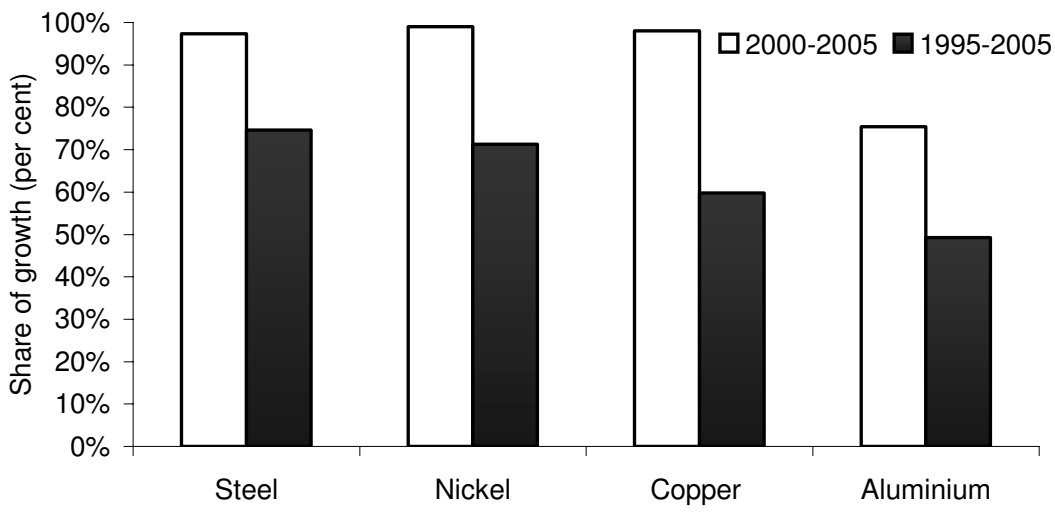

Source: Plotted using the data from Macquarie Research Metals and Mining 2004 and data for 2004 and 2005 are from Chinese Mining and Resource (http://www.ChinaMR.net). 


\section{Figure 14.8 World copper consumption per capita, 1905-2005}

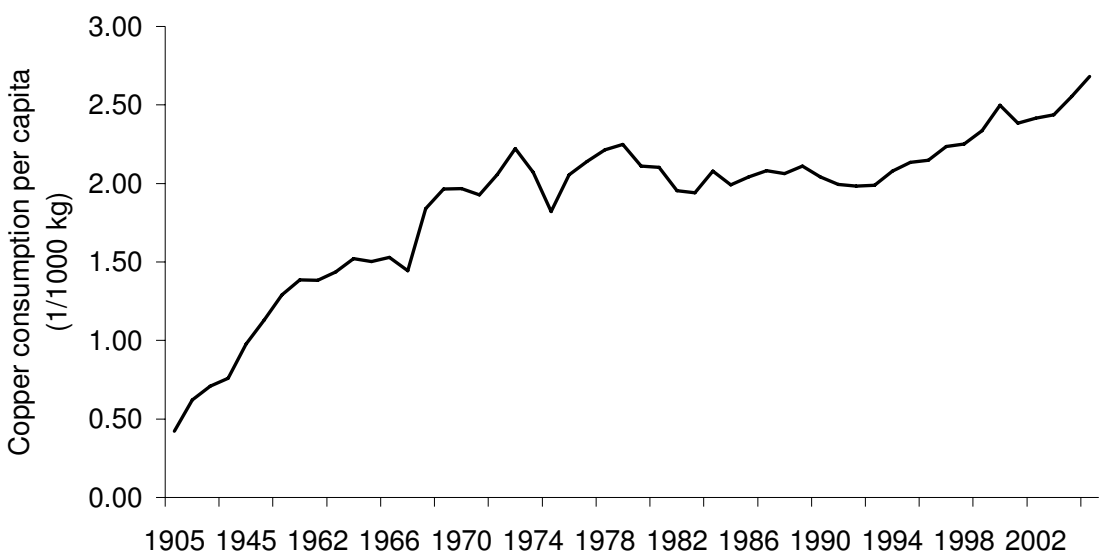

Source: Plotted using data from Macquarie Research Metals and Mining 2004.

Figure 14.9 The copper price of the world in 2004 US dollars, 1895August 2006 (US dollar/tonne)

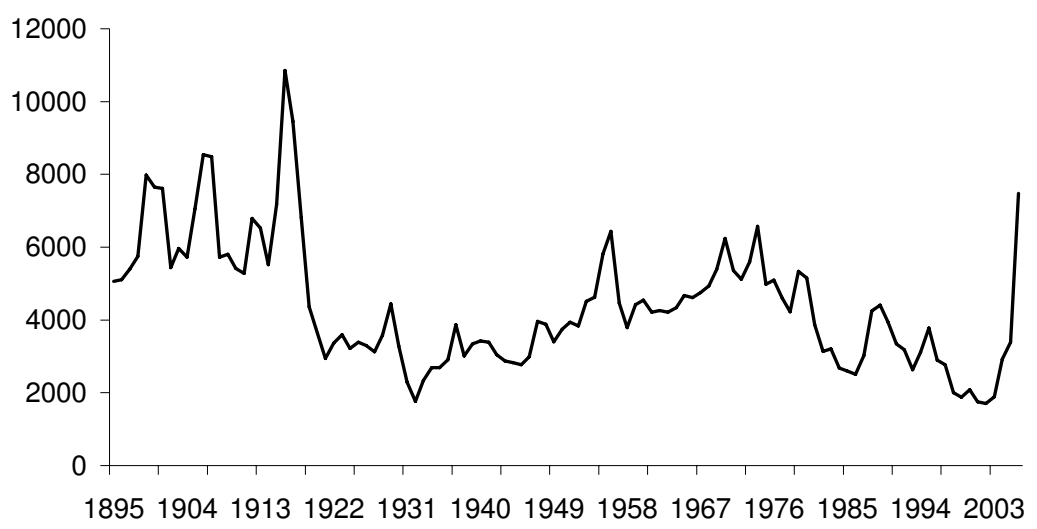

Source: Plotted using the data from Westpac Economic Research with authors' updating. 
legacy of central planning. There is considerable scope for increased energy efficiency in future, including through the bringing of all prices to international levels, although considerably less than the gains that have already been achieved.

We have already noted that in Northeast Asia, high energy intensity in economic growth has been associated with rapid urbanisation, high investment shares of output, and high and increasing export orientation after the turning point in economic development. The high energy intensity of growth through the middle stages of industrialisation has been observed in other economies as well. For example, it was present in the United Kingdom through the middle decades of the nineteenth century (Humphrey and Stanislaw, 1979:41), with energy intensity of growth later falling to relatively low levels.

Over the past half century, the relationship between global petroleum demand in particular, and global prices, has been very different from the corresponding relationship for metals. For a long period, from the end of the Second World War until around the time of the oil crisis in 1973-74, global demand grew strongly, while prices in real terms were stable at low levels, or falling (Figures 14.12 and 14.13). The difference derives from the special circumstances of supply in the petroleum industry. The new political circumstances of the Middle East after the

\section{Figure 14.10 China's shares of demand growth for four metals, 1995-2005}

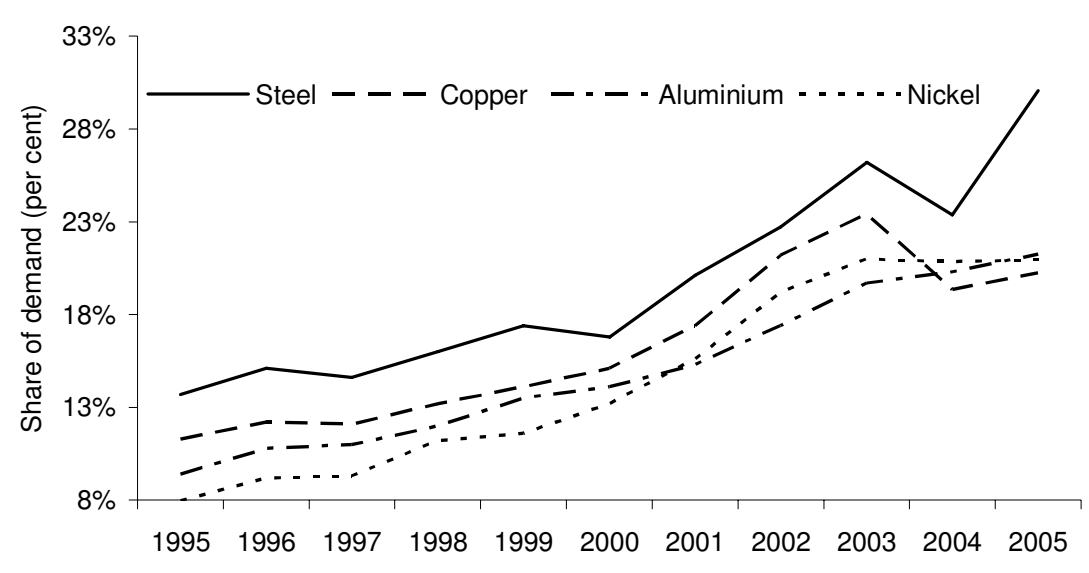

Source: Plotted using the data from Macquarie Research Metals and Mining 2004 and data for 2004 and 2005 are collected from websites of Chinese Mining and Resource (www.ChinaMR.net) 
Figure 14.11 Energy production and consumption in China, 1989-2005 (100 million metric tonnes oil equivalent)

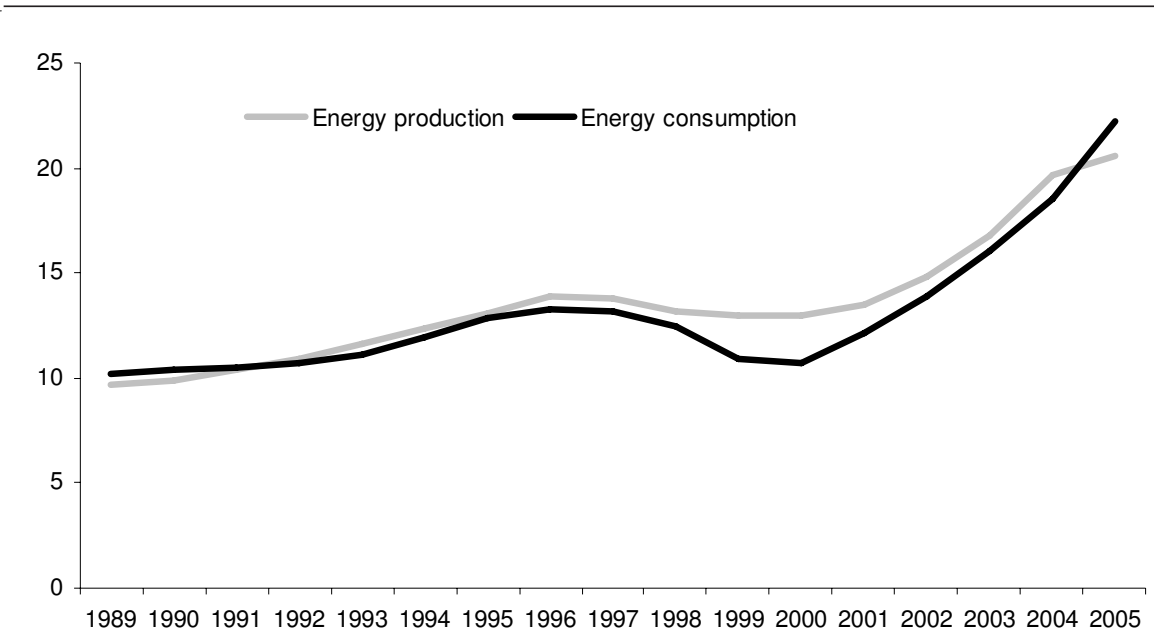

Source: China Industrial Maps (2005) and authors' own calculation using the data from BP energy statistics for 2005.

Figure 14.12 Growth rates of demand for petroleum: Northeast Asia and the world, 1961-2005 (per cent)

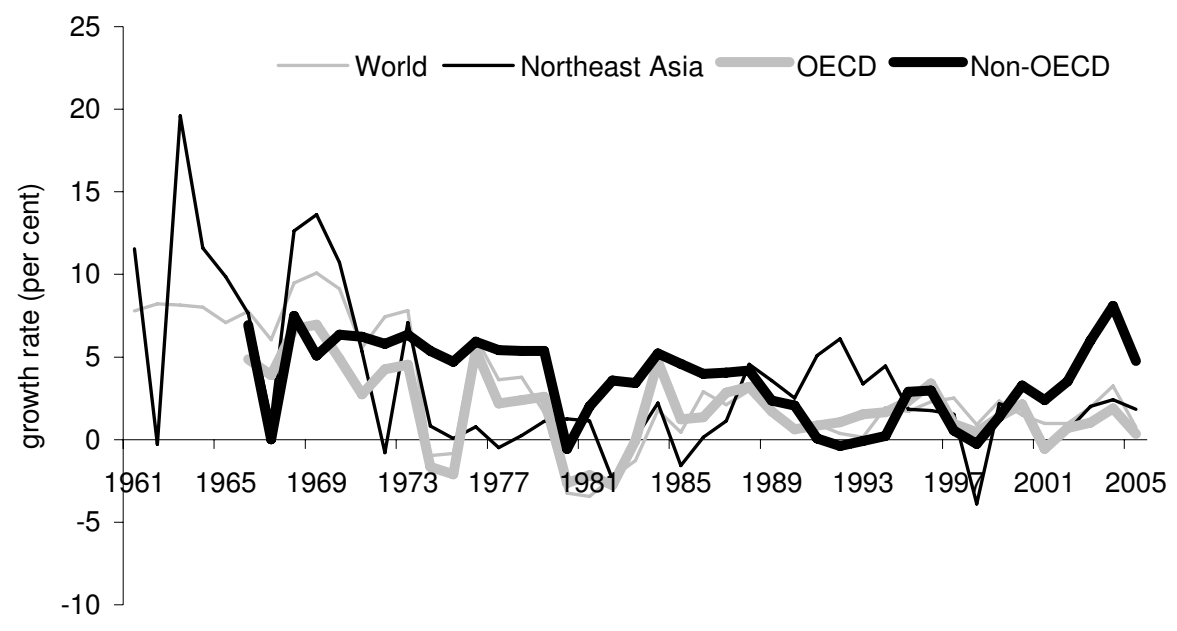

Source: Calculated using the data from US Department of Energy. 
Second World War were conducive to rapid expansion of oil supply capacity. Uncertainty about the continuation of those conditions encouraged rapid rates of depletion of known reserves, even when prices were judged to be lower than average expectations of prices in later years.

The industrialisation of Japan and later Korea therefore occurred in an environment of abundant cheap oil. The Northeast Asian share of global oil consumption rose strongly, at first mainly through Japanese demand, and later through Korea.

The oil market began to tighten in advance of the OPEC-led restrictions on supply in the early 1970s-indeed, this tightening can be seen as establishing the conditions for effective action by the OPEC cartel. Constrained supply growth and higher prices were reflected quickly in lower rates of demand growth. Chinese demand growth became a major element in the global petroleum story from the mid 1990s, and especially from 2005 when China suddenly became a large net importer of energy, mainly in the form of petroleum. High growth and energy intensity of growth and the fact that almost all of the increment in demand will now be met from imports ensures that the Chinese influence on the world petroleum market will continue to grow. That influence is correctly credited for much of the price increases in 2005 and early 2006. The China influence will be greater in future, mainly for petroleum, but also for natural resources that are required in a wide range of alternative energy sources, notably uranium.

\section{The Chinese impact on global markets}

So long as the established path of rapid economic growth in China is not disrupted by internal or external political dislocation, the pressure of Chinese demand on global resources markets is in its early and moderate stages. Lin (Chapter 4, this volume) discusses the likelihood that Chinese output will quadruple over the next two decades, and the possibility that it will grow at a rate that will cause it to increase almost eight-fold over that same period. From one perspective that is not at all surprising or even novel-the greater of these prospects requires a rate of growth that was close to being achieved over two decades and longer by Japan, Korea, Taiwan and Hong Kong and Singapore, and by China itself in the first quarter century of reform continuing to today. The larger current gap between domestic productivity levels and the world frontiers, the unprecedentedly high investment rates (Garnaut and Huang 2005), and the extraordinarily rapid rate of integration into the international economy (at least in comparison with Japan and Korea) suggest the reasonableness of higher expectations.

For reasons explained in this chapter, China is now entering a stage of growth in which the relationship between incremental output and incremental demand for energy 
Figure 14.13 Crude oil price adjusted for inflation, 1946-July 2006 (constant 2005 US\$)

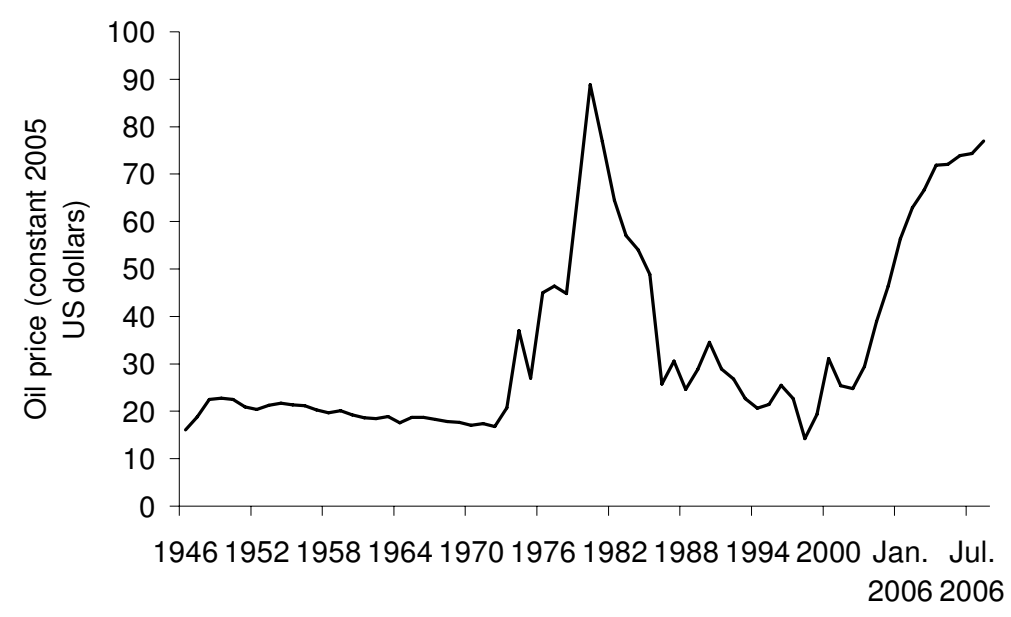

Source: Plotted using the data from http://www.iea.org/Textbase/stats/oilresult.asp and www.eia.doe.gov/.

and metals is exceptionally strong. As China's absolute and proportionate economic size increases over time, the same rate of growth, and the same intensity of resource use in economic output, generates absolutely and proportionately larger effects on total global demand. And with Chinese domestic production of almost all resourcebased commodities rising at a substantially lower rate than domesticdemand as a proportion of global production, consumption and international trade.

The interaction of these realities will cause Chinese pressure on world markets for resources over the next two decades at least to be proportionately larger and maintained over a longer period than that exerted by industrialising Japan in the 1950 s and 1960s. The increase in metals' demand over this period may be comparable to the total of the industrial world's demand today. The increment in Chinese energy demand may be proportionately a bit more modest, because of the exceptional conditions that support current North American demand, the supply constraints on energy in its most economically convenient form (liquid petroleum) and the global environmental conditions that may constrain the use of energy in its present form. 
It is therefore likely that global prices will need to be sustained on the high track for the foreseeable future- at average levels that provide incentives for continued rapid growth in supply over a long period.

\section{How will those prices compare with the exceptional levels of August 2006?}

Metals' prices will not be as high on average as they are at present, because current prices provide ample incentives for new investment and adequate expansion of global production capacity. But they will remain on average much higher in real terms—for most metals, perhaps twice as high—as they did during the slow global growth in global metals' demand of the last quarter of the twentieth century.

The story for energy prices is complicated by the geological and economic constraints on petroleum supply, especially in liquid form. The balancing of global demand (augmented by rapid growth in China), would require continually rising liquid petroleum prices if there were no opportunities for substitution. However, at current prices, a wide range of capital-intensive substitutes for liquid petroleum are economically viable - conversion of gas to liquids, coal to liquids, oil from shale and tar sands, bio-fuels of various kinds and, for the generation of electricity, nuclear energy, so long as markets come to reflect the view that oil prices of at least forty to fifty dollars - two thirds of today's levels—are here to stay. Over time, it is likely that energy prices will head back towards those levels, although the uncertainty about future prices and commercially new technologies and the immense capital requirements could hold prices up above the average long-term levels for many years. In the meantime, with continued strong pressure on global oil supplies, the concentration of global production in locations that are vulnerable to political instability and disruption of supply will generate spikes of higher prices from time to time.

For China, the relatively rich per capita endowment of coal resources will, in the absence of an effective international regime to control 'greenhouse' emissions, support disproportionately large expansion of energy supply from that source. That would go some limited way to ameliorating Chinese demand pressures on global energy markets.

\section{Resource limits to growth?}

The most important constraint on metals and energy supplies being available to meet the 'natural' growth in Chinese demand is environmental (see Chapter 17 by McKibbin, this volume). Local environmental problems within China are likely to be solved over time through changes in preferences between environmental 
amenity and other forms of consumption, and associated reallocation of priorities, as incomes rise. The global environmental pressures, and especially global warming problems described as the 'greenhouse effect', are less tractable.

The costs through the greenhouse effect of one country's consumption of fossil fuels are mainly external to that country. It follows that in the absence of an effective international regime with the effect of internalising the external costs, economic rather than environmental considerations will limit their use. In these circumstances, China will meet a high proportion of its energy requirements from fossil fuels in relatively damaging forms, particularly coal, much of it with low ratios of energy generation to greenhouse emissions. It is likely that, within two decades, Chinese emissions would exceed those of all of the currently industrial countries together. The environmental damage would be immense, but for the world as a whole, and not particularly for China.

The likelihood that other large developing countries, first of all Brazil and India, would be generating rapidly increasing quanta of emissions, and over time becoming large sources of pressures for global change, would exacerbate the global problem. India is currently well behind China as a source of emissions. Continued rapid growth at the rate of the post reform era (that is, through the 1990s and early twentieth century) will mean that India in two decades time will potentially be as large a source of greenhouse emissions as China today, with the likelihood of continuing to expand at a rapid rate after the rate of increase has eased in China.

Such statement of the obvious facts argues its own case for an effective international greenhouse regime. So far in human history, however, necessity has not been the mother of invention in the field of international institutions. But if an effective international regime were established, it would greatly increase pressure to expand capacity to supply energy from sources other than fossil fuels, to a point that would require even higher prices for energy than those that are in contemplation as a result of Chinese and global economic developments.

Under any of the possible scenarios, China's imports of metals and energy from the rest of the world will rise to levels well beyond those of any other country at any time. This alone will give China a powerful interest in political stability throughout the world, including around the global transport networks through which its requirements would be supplied. China will have powerful incentives to innovate in the development of the political and economic institutions that would encourage production of minerals and their substitutes for world markets. It would be one more factor compelling China into a global political role, whatever the proclivities of its leadership from time to time. 